desirability and feasibility of a European geophysical union. By the end of the meeting the union had become a society, but the original wording left the participants in no doubt as to the source of the inspiration. The proportion of Europeans who attend the annual meeting of the American Geophysical Union (AGU) may be fairly small; but it is clear that many Europeans hold these meetings in high regard. Indeed, the most commonly mentioned justification for a European geophysical society (EGS) was that the proposed annual meetings would give the younger scientists in Europe greater opportunity to present their ideas in public and to benefit from contact with more experienced scientists from all the Earth and planetary sciences. This is just the function that the annual meetings of the AGU fulfil so well.

Both of the EGS gatherings in Madrid comprised free ranging discussions, although ultimately several important policy statements emerged. First, although national geophysical societies should be consulted, it was generally agreed that only a new organization with individual membership would enable the right emphasis to be placed on contributions from the less established geophysicists. Second, the most important function of the EGS would be the organization of annual meetings, probably in a different European city each year. The possibility of a new journal was thus ruled out, although the EGS must clearly produce some sort of bulletin or news letter to keep its members informed of its activities. The date for the first meeting was set at January 1971 .

One of several problems which clearly worried some participants was the proliferation of meetings, which is beginning to be regarded with the same distaste as the proliferation of journals. Even now, it is possible for a geophysicist to spend about half of each year at conferences. As the EGS meetings develop, however, they could serve as a focus for meetings of other European associations in Earth sciences and thus reduce rather than increase the time devoted to conferences. A second source of discontent for some was the use of the word geophysical in the title of the proposed organization. Fortunately, Dr E. Waldo Smith, executive director of the American Geophysical Union, was on hand to explain how that organization has dealt with such critieisms. Geophysics must be defined to include the study of the Earth from its core to the outermost limits of its environment. It is clearly necessary, however, to limit the field in some way; and in practice the AGU has found that the use of the term geophysical ensures the inclusion of subjects peripheral to what is commonly understood as geophysics, but at the same time discourages the inclusion of every Earth science-for example, the bulk of what is generally regarded as pure geology.

The participants left the organizers of the two meetings in no doubt as to the degree of enthusiasm for an EGS. The next step will thus be to organize a meeting of national representatives to hammer out the scientific, financial and administrative structure of the proposed society. In the meantime, Mr C. R. Argent (Royal Society, London) and Dr Peter J. Smith (Department of Geophysics, University of Liverpool) are acting as interim secretaries. They are building up a mailing list of individuals in Europe and elsewhere who are interested in, and wish to be kept informed of, the progress of the EGS.
POPULATION

\section{Signs of Change}

\section{from our Demography Correspondent}

Demographers from more than 60 countries left the London School of Economics at the end of the conference of the International Union for the Scientific Study of Population with a confidence stemming from the rapid development of the subject in recent. years, and the belief that they have an important contribution to make to the formulation of general social and economic policies.

Projections of world population no longer startle, but they are significant enough to demand a reappraisal of the policies of governments in both the developed and developing worlds with regard to level of population and growth rates. The session on population policies divided naturally into two sections focused on the problems of policy in developed and developing countries. In the short term these will be different. In the developed world the old pro-natalist policies based on prohibition of contraception and abortion are rapidly becoming untenable and reliance on fiscal methods is at present the only method open to governments to influence the trend of population growth.

In the developing countries the signs of a decline in fertility are beginning to be seen. M. Boserup (Institute of Economics, Copenhagen University) attributed this to a generation effect of the decline in mortality which has occurred since the Second World War, on persons who have grown up in large families and do not wish their children to have the same experience. Government policies in the developing world are polarized into the "Indian" model where the emphasis is on the need to reduce births to aid economic development, and the "Latin American" model, which places economic motives second to the health and family welfare aspects of birth control. Current experience in western countries, however, shows that measures with a social context may directly contradict population policies formulated in purely economic terms. Rescinding family allowances is a method which has been advocated as a depressant on the birth rate, but its political implications are obvious.

In the long term, a world wide policy to reduce the rate of growth to zero will be necessary. The moot point is whether this can be achieved by fiscal means alone, albeit harsh, or whether direct interference will be necessary, perhaps in the form of child licences. Conference participants were, unfortunately, remarkably reluctant to discuss this. This dilemma of demographers stems from their treatment of the population as an aggregate, whereas policies affect individuals. If demographers hold that a current rate of growth is undesirable, whom do they expect to take action? Is it to be only persons who would prefer large families, or must all couples be prepared to accept one child, or more, less ?

Questions such as these cannot be answered in a purely statistical manner, and if one theme should be extracted from the conference, it is that demographers are paying increasing attention to the social, economic and political ramifications of population growth and attempting to incorporate these into projections. So far they have tended to keep out of political controversy over population, but this should become a thing of the past. 